\title{
Synthesis and Luminescent Properties of Strontium Cerium Oxide Phosphors Doped with Rare Earths
}

\author{
C. A. Rao $^{1^{*}}$, P. R. V. Nannapaneni ${ }^{2}$, and K. V. R. Murthy ${ }^{3}$ \\ ${ }^{1}$ Department of Physics, VRS and YRN College, Chirala-523 155, AP, India \\ ${ }^{2}$ Department of Physics, IIIT [Basar], Rajiv Gandhi University of Knowledge Technologies \\ [RGUKT]-504101, AP, India \\ ${ }^{3}$ Display Materials Laboratory, Applied Physics Department, Faculty of Technology \& Engineering, \\ M.S University of Baroda, Baroda-390 001, India
}

Received 22 June 2012, accepted in final revised form 21 December 2012

\begin{abstract}
In this paper we report the synthesis and luminescent properties of $\mathrm{Sr}_{2} \mathrm{CeO}_{4}$ doped with rare earths $(0.5 \%$ concentration of $\mathrm{La}, \mathrm{Eu}$ and $\mathrm{Dy}$ ions) are reported. The powder samples of rare earths doped strontium cerium oxide $\left(\mathrm{Sr}_{2} \mathrm{CeO}_{4}: \mathrm{La}, \mathrm{Eu}\right.$ and $\mathrm{Dy}$ ions) was synthesized by a standard solid state reaction method in air at $1200^{\circ} \mathrm{C}$. These samples were characterized by X-ray diffraction, scanning electron microscope (SEM) and photoluminescence (PL) techniques, particle size analysis. The XRD data revealed that the structure of the $\mathrm{Sr}_{2} \mathrm{CeO}_{4}$ as orthorhombic and the calculated average crystallite size is $\sim 10 \mathrm{~nm}$. Scanning electron microscopy revealed that the $\mathrm{Sr}_{2} \mathrm{CeO}_{4}$ phosphor particles had non-spherical shape and the irregular shaped particles are highly agglomerated. PL excitation and emission spectra of $\mathrm{Sr}_{2} \mathrm{CeO}_{4}$ doped with rare earths are recorded at room temperature. The CIE coordinates depicted on 1931 chart of $\mathrm{Eu}(0.5 \%)$ doped $\mathrm{Sr}_{2} \mathrm{CeO}_{4}$ shown that the emission colour varies from blue to white. This phosphor has a good potential for application in white light LEDs.
\end{abstract}

Keywords: Inorganic compounds; Solid-state reaction; X-ray diffraction; Photoluminescence; CIE; LED; SEM; Particle size analysis.

(C) 2013 JSR Publications. ISSN: 2070-0237 (Print); 2070-0245 (Online). All rights reserved. doi: http://dx.doi.org/10.3329/jsr.v5i1.10965 J. Sci. Res. 5 (1), 1-11 (2013)

\section{Introduction}

Recently various phosphor materials have been actively investigated to improve their luminescent properties and to meet the development of different display and luminescence devices. Inorganic compounds doped with rare earth ions form an important class of phosphors as they possess a few interesting characteristics such as excellent chemical stability, high luminescence efficiency, and flexible emission colors with different

\footnotetext{
* Corresponding author: atchyyuth@gmail.com
} 
activators[1,2]. Rare earth ions doped phosphors have been used in varied fields based on their electronic and optical characters arising from their $4 \mathrm{f}$ electrons. Among the rare earth elements, europium is a special element as dopant, because it exhibits the property of valence fluctuation, i.e., the valence state is divalent or trivalent [3]. In 1998, a blue phosphor compound, $\mathrm{Sr}_{2} \mathrm{CeO}_{4}$ possessing one-dimensional chain of edge-sharing $\mathrm{CeO}_{6}$ octahedra, was identified by Danielson and his co-workers with combinatorial chemistry [4]. It exhibited a blue-white emission band that peaks at $485 \mathrm{~nm}$ at $254 \mathrm{~nm}$ excitation and the luminescence was suggested to originate from a ligand-to-metal $\mathrm{Ce}^{4+}$ charge transfer. This material was analyzed by Rietveld structural refinement, and the luminescent phase was characterized as $\mathrm{Sr}_{2} \mathrm{CeO}_{4}$ with orthorhombic structure containing one-dimensional chains of edge-sharing $\mathrm{CeO}_{6}$ octahedra that are linked together by $\mathrm{Sr}^{2+}$ ions. This material exhibits excellent luminescent property and maximum emission band around 485nm, whose intensity changes depending on the employed heat treatment. Some impurity phases such as $\mathrm{SrCO}_{3}, \mathrm{SrCeO}_{3}$ and $\mathrm{CeO}_{2}$ were also detected [5-7]. Some authors [8-10] have assigned the luminescence of the $\mathrm{Sr}_{2} \mathrm{CeO}_{4}$ material to the charge transfer between $\mathrm{Ce}^{4+}$ and $\mathrm{O}^{2-}$ because the position and shape of the absorption band and the emission band width are characteristic for this type of transition. Some authors have observed that the strong luminescence of $\mathrm{Sr}_{2} \mathrm{CeO}_{4}$ makes it potentially applicable as blue phosphor material in low pressure mercury vapor lamps [11] and FED [12, 13] as well as other types of luminescence devices [14]. Following this observation, several studies about this luminescent material have been conducted, and some synthetic routes have been developed for the preparation of $\mathrm{Sr}_{2} \mathrm{CeO}_{4}$ powders. Here we report the preparation and characterization of blue phosphor $\mathrm{Sr}_{2} \mathrm{CeO}_{4}$ doped with rare earths $(0.5 \mathrm{~mol} \%$ concentration only) La, Eu and Dy ions via standard solid state reaction method in air.

\section{Experimental Method}

Strontium nitrate $\left[\mathrm{Sr}\left(\mathrm{NO}_{3}\right)_{2}\right]$, Cerium oxide $\left(\mathrm{CeO}_{2}\right)$, Lanthanum oxide $\left(\mathrm{La}_{2} \mathrm{O}_{3}\right)$, Europium oxide $\left(\mathrm{Eu}_{2} \mathrm{O}_{3}\right)$ and Dysprosium oxide $\left(\mathrm{Dy}_{2} \mathrm{O}_{3}\right)$ were used as starting materials to prepare $\mathrm{Sr}_{2} \mathrm{CeO}_{4}$ and rare earth doped phosphors.Every starting material was of greater than 99.9\% purity. All the starting materials were weighed according to the stoichiometric ratio. $\mathrm{Sr}_{2} \mathrm{CeO}_{4}$ phosphor and other samples of $\mathrm{Sr}_{2} \mathrm{CeO}_{4}$ doped with rare earths $(0.5 \%$ concentration of La, Eu and Dy ions) were prepared via solid state reaction method (SSR). A stoichiometric mixture of these staring powders was thoroughly homogenized in an agent mortar for $1 \mathrm{hr}$ and then put into an alumina crucible. The homogenized mixture was heated in air at $12000 \mathrm{C}$ for $3 \mathrm{~h}$ in a muffle furnace with a heating rate of $50 \mathrm{C} / \mathrm{min}$. Finally the samples were allowed to cool down to room temperature for about $20 \mathrm{~h}[15,16]$. All the samples were again ground into fine powder using agate mortar and pestle about an hour.

Several complementary methods were used to characterize the prepared phosphors. To identify the crystal phase, X-ray diffraction (XRD) analysis was carried out with a powder X-ray diffractometer (Indus beam line-II (ADXRD BL-12),RRCAT, Indore, India), Photoluminescence (PL) emission spectra were measured by a Spectrofluorophotometer 
(SHIMADZU, RF-5301 PC using Xenon lamp as excitation source. The morphologies of particles were investigated by using Scanning electron microscope (PHILIPS XL 30 CP). The particle size was measured by using Laser based particle size analysis (Malvern Instrument Ltd (U.K), The CIE (Commission International de l'Eclairage) co-ordinates were calculated by the Spectrophotometric method using the spectral energy distribution.

\section{Results and Discussion}

\subsection{X-ray diffractometry}

The typical XRD pattern of $\mathrm{Sr}_{2} \mathrm{CeO}_{4}$ is shown in Fig. 1 and all the diffraction peaks can be well indexed based on the ICDD No.89-5546 [17]. All the prepared samples are characterized to be single phase $\mathrm{Sr}_{2} \mathrm{CeO}_{4}$ of orthorhombic structure. Except this, no other phase exists in the XRD spectra, indicating that the as-prepared $\mathrm{Sr}_{2} \mathrm{CeO}_{4}$ phosphor is single phase.XRD study confirms the single phase $\mathrm{Sr}_{2} \mathrm{CeO}_{4}$ with the orthorhombic structure. The calculated crystallite sizes using Scherer's formula $D=K . \lambda \beta \cos \theta$, where k the constant (0.94), $\lambda$ the wavelength of the X-ray $(0.895 \AA), \beta$ the full-width at half maxima (FWHM), $\theta$ the Bragg angle of the XRD is around $\sim 9 \mathrm{~nm}$ (un-doped), La doped $\mathrm{Sr}_{2} \mathrm{CeO}_{4}$ is around $\sim 11 \mathrm{~nm}$, Eu and Dy doped $\mathrm{Sr}_{2} \mathrm{CeO}_{4}$ is around $\sim 10 \mathrm{~nm}$. No change in the crystal structure on doping rare earths in host material.

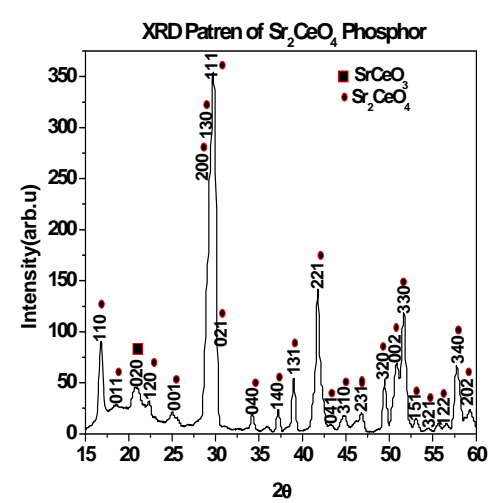

Fig. 1. XRD Pattern of $\mathrm{Sr}_{2} \mathrm{CeO}_{4}$ heated at $1200^{\circ} \mathrm{C}$.

\subsection{SEM analysis}

Fig. 2 shows the SEM photograph of $\mathrm{Sr}_{2} \mathrm{CeO}_{4}$ phosphor particles. The $\mathrm{Sr}_{2} \mathrm{CeO}_{4}$ phosphor particles had non-spherical shape and the irregular shaped particles are highly agglomerated. Fig. 3 is the typical SEM photograph of the synthesized $\mathrm{Sr}_{2} \mathrm{CeO}_{4}$ : Dy phosphor. The multi layered structure was observed. The prominent characteristic of $\mathrm{Sr}_{2} \mathrm{CeO}_{4}$ : Dy crystal growth is a serious anisotropic growth rate. The growth rate along the 
$a b$ plane is $\sim 5$ times larger than that along $c$-axis. This phenomenon can be easily understood from the periodic bond chain (PBC) theory. The fundamental building units are in the orthorhombic structure. Fig. 4 shows the SEM photograph of $\mathrm{Sr}_{2} \mathrm{CeO}_{4}$ : $\mathrm{Eu}(0.5 \%)$ and it exhibits the grains like irregular sizes and shapes which are highly agglomerated.

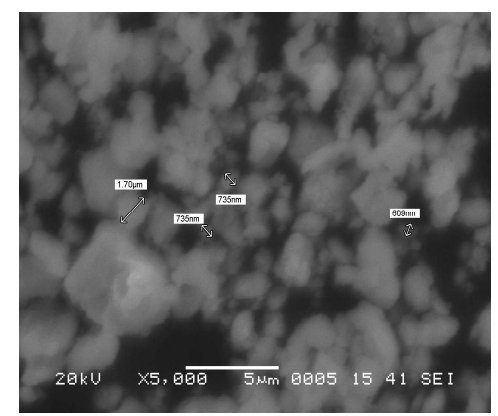

Fig. 2. SEM photograph of $\mathrm{Sr}_{2} \mathrm{CeO}_{4}$ prepared from solid state reaction method.

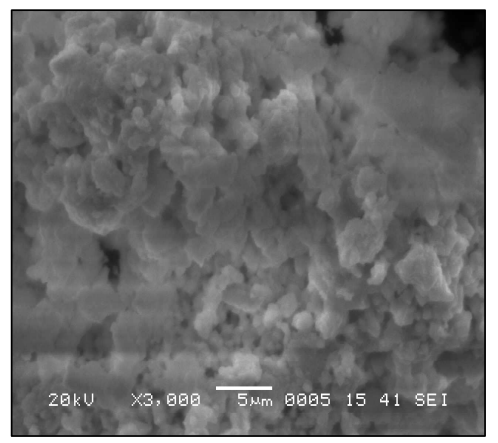

Fig. 3. SEM photograph of $\mathrm{Sr}_{2} \mathrm{CeO}_{4}$ doped with Dy (0.5\%).

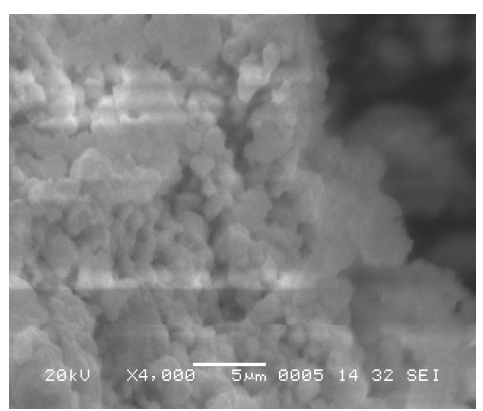

Fig. 4. SEM photograph of $\mathrm{Sr}_{2} \mathrm{CeO}_{4}$ doped with $\mathrm{Eu}(0.5 \%)$. 


\subsection{Photoluminescence study}

Fig. 5 shows the PL excitation and emission spectra of $\mathrm{Sr}_{2} \mathrm{CeO}_{4}$ particles recorded at room temperature. The emission spectra of $\mathrm{Sr}_{2} \mathrm{CeO}_{4}$ excited at $250 \mathrm{~nm}$ show a broad band in the region of $350-650 \mathrm{~nm}$ with a peak at $470 \mathrm{~nm}$. The CT band can be assigned to the $\mathrm{f} \rightarrow \mathrm{t}_{1} \mathrm{~g}$ transitions of $\mathrm{Ce}^{4+}$ ions. The emission spectra of $\mathrm{Sr}_{2} \mathrm{CeO}_{4}$ observed with $260 \mathrm{~nm}$ excitation is similar to that observed with $250 \mathrm{~nm}$ excitation. The only difference is the emission intensity under $260 \mathrm{~nm}$ excitation is higher than $250 \mathrm{~nm}$. The emission at $470 \mathrm{~nm}$ is considered as a potential blue emitting phosphor. The excitation spectrum recorded for $\mathrm{Sr}_{2} \mathrm{CeO}_{4}$ displays a broad band and peaks at $250 \mathrm{~nm}$ and $260 \mathrm{~nm}$ which is attributed to the $\mathrm{Ce}^{4+}-\mathrm{O}$ distances in the lattice.

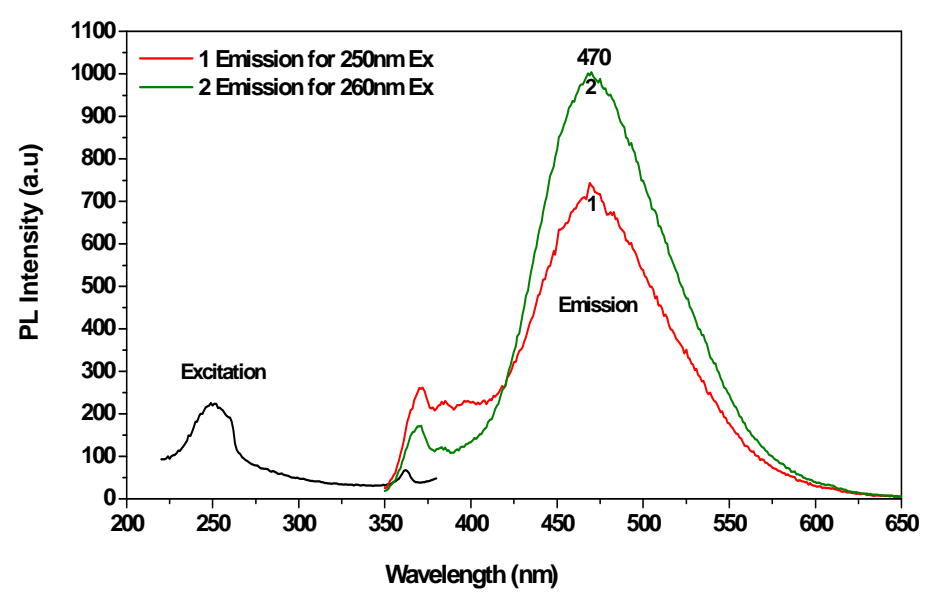

Fig. 5. Excitation and emission spectra of $\mathrm{Sr}_{2} \mathrm{CeO}_{4}$ phosphor.

Fig. 6 shows the PL excitation and emission spectra of $\mathrm{La}(0.5 \%)$ doped $\mathrm{Sr}_{2} \mathrm{CeO}_{4}$ phosphor. The sample exhibit the emission peak at $470 \mathrm{~nm}$ upon the excitation at $250 \mathrm{~nm}$ and $260 \mathrm{~nm}$. The PL emission intensity at $260 \mathrm{~nm}$ excitation is $40 \%$ more than that $250 \mathrm{~nm}$ excitation. Due to the Ce sites were replaced by La ions, the charge transfer emission intensity decreased by $60 \%$ than that of $\mathrm{Sr}_{2} \mathrm{CeO}_{4}$ phosphor. Fig. 7 shows the PL excitation and emission spectra of Dy $(0.5 \%)$ doped $\mathrm{Sr}_{2} \mathrm{CeO}_{4}$ phosphor. The sample exhibit the peaks at $469 \mathrm{~nm}$ and $575 \mathrm{~nm}$ upon the excitation at $250 \mathrm{~nm}$ and $260 \mathrm{~nm}$. These peaks are assigned to the ${ }^{4} \mathrm{~F}_{9 / 2}-{ }^{6} \mathrm{H}_{15 / 2}$ and ${ }^{4} \mathrm{~F}_{9 / 2}-{ }^{6} \mathrm{H}_{13 / 2}$ transitions, respectively. Dy is well resolved in the host phosphor at $575 \mathrm{~nm}$ in yellow region. The PL emission intensity at $260 \mathrm{~nm}$ excitation is sharper than that of $250 \mathrm{~nm}$ excitation. 


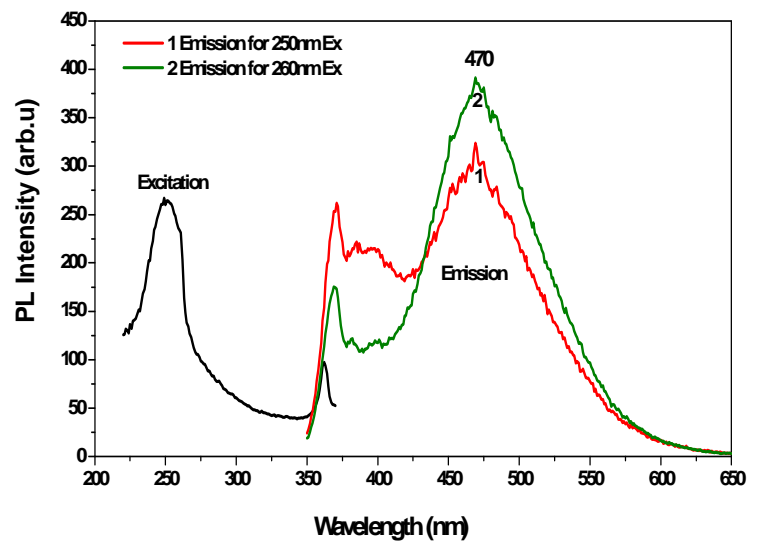

Fig. 6. Excitation and emission spectra of $\mathrm{La}(0.5 \%)$ doped $\mathrm{Sr}_{2} \mathrm{CeO}_{4}$ phosphor.

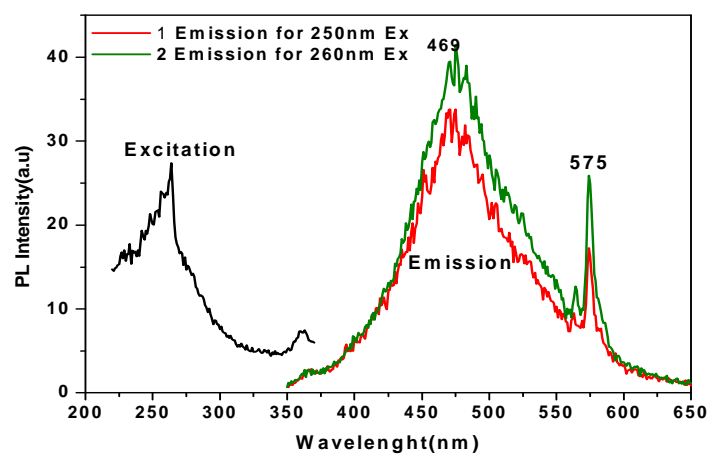

Fig. 7. Excitation and emission spectra of Dy (0.5\%) doped $\mathrm{Sr}_{2} \mathrm{CeO}_{4}$ phosphor.

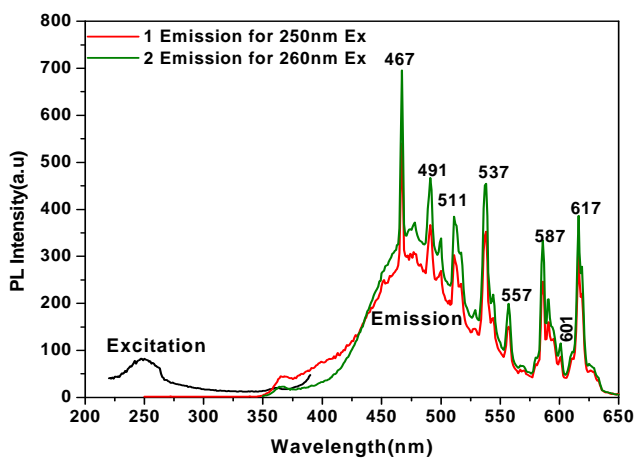

Fig. 8. Excitation and emission spectra of $\mathrm{Eu}(0.5 \%)$ doped $\mathrm{Sr}_{2} \mathrm{CeO}_{4}$ phosphor. 
Fig. 8 shows the PL excitation and emission spectra of $\mathrm{Eu}(0.5 \%)$ doped $\mathrm{Sr}_{2} \mathrm{CeO}_{4}$ phosphor. The sample exhibit the emission peaks at 467, 491, 511, 537, 557, 587,601 and $617 \mathrm{~nm}$ upon the excitation at $250 \mathrm{~nm}$ and $260 \mathrm{~nm}$. These peaks are assigned to the ${ }^{5} \mathrm{D}_{2} \rightarrow{ }^{7} \mathrm{~F}_{1,2,3},{ }^{5} \mathrm{D}_{1} \rightarrow{ }^{7} \mathrm{~F}_{1,2}$, and also from ${ }^{5} \mathrm{D}_{0} \rightarrow{ }^{7} \mathrm{~F}_{1,2}$ transitions respectively. The peak around $610-620 \mathrm{~nm}$ is due to the electric dipole transition of ${ }^{5} \mathrm{D}_{0} \rightarrow{ }^{7} \mathrm{~F}_{2}$, which is induced by the lack of inversion symmetry at the Eu ${ }^{3+}$ sites. It is well known that the ${ }^{5} \mathrm{D}_{0} \rightarrow{ }^{7} \mathrm{~F}_{2} /$ ${ }^{5} \mathrm{D}_{0} \rightarrow{ }^{7} \mathrm{~F}_{1}$ intensity ratio is a good measure of the site symmetry of rare-earth ions in a doped material. The observed PL emission of Eu doped $\mathrm{Sr}_{2} \mathrm{CeO}_{4}$ may be due to crystal field effect and unusual luminescent property due to low vibration energy of $\mathrm{Sr}_{2} \mathrm{CeO}_{4}$ host lattice and different energy transfer process from host to dopant. The high efficiency energy transfer allows us to expect that the $\mathrm{Sr}_{2} \mathrm{CeO}_{4}$ crystal structure could form the base for phosphors with different spectral emissions [18-21]. The $\mathrm{Eu}(0.5 \%)$ doped $\mathrm{Sr}_{2} \mathrm{CeO}_{4}$ phosphor displays all the colours led to white light emission. Therefore this phosphor can be good has a good potential for application in white light LED's.

\subsection{Particle size analysis}

The particle size distribution histogram of $\mathrm{Sr}_{2} \mathrm{CeO}_{4}$ and $\mathrm{La}$, Eu, Dy doped $\mathrm{Sr}_{2} \mathrm{CeO}_{4}$ phosphors shown in Figs. 9 to 12. The particle size of prepared phosphor specimen was measured by using laser based system, Malvern Instrument, U.K. The mean diameter of the particle size of $\mathrm{Sr}_{2} \mathrm{CeO}_{4}$ phosphor specimen is $26 \mu \mathrm{m}$, $\mathrm{La}$ doped $\mathrm{Sr}_{2} \mathrm{CeO}_{4}$ specimen is $18.31 \mu \mathrm{m}$, Eu doped $\mathrm{Sr}_{2} \mathrm{CeO}_{4}$ specimen is $17 \mu \mathrm{m}$ and Dy doped $\mathrm{Sr}_{2} \mathrm{CeO}_{4}$ specimen is $32 \mu \mathrm{m}$. The average particle diameter of europium doped $\mathrm{Sr}_{2} \mathrm{CeO}_{4}$ phosphor is $17 \mu \mathrm{m}$ and the crystallite size is around $10 \mathrm{~nm}$.

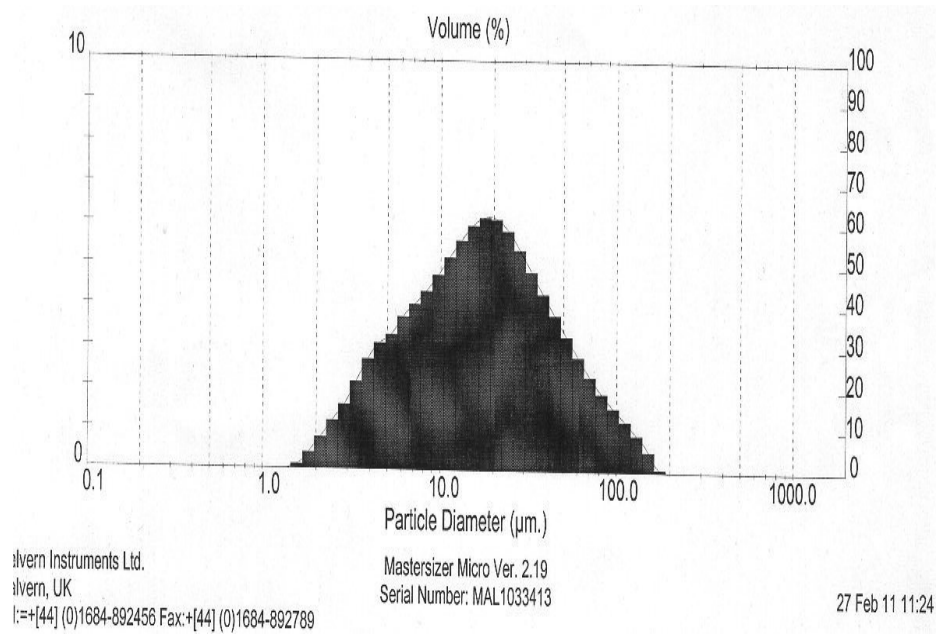

Fig. 9. Particle size distribution histogram of $\mathrm{Sr}_{2} \mathrm{CeO}_{4}$. 


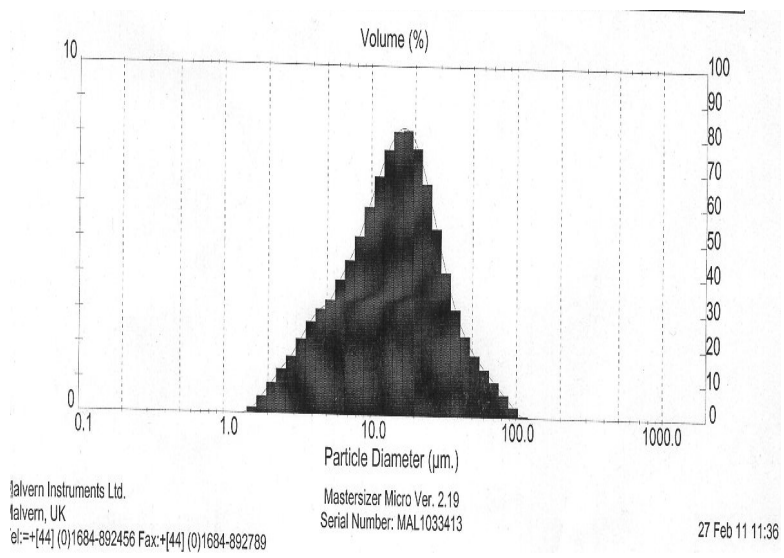

Fig. 10. Particle size distribution histogram of $\mathrm{La}$ doped $\mathrm{Sr}_{2} \mathrm{CeO}_{4}$.

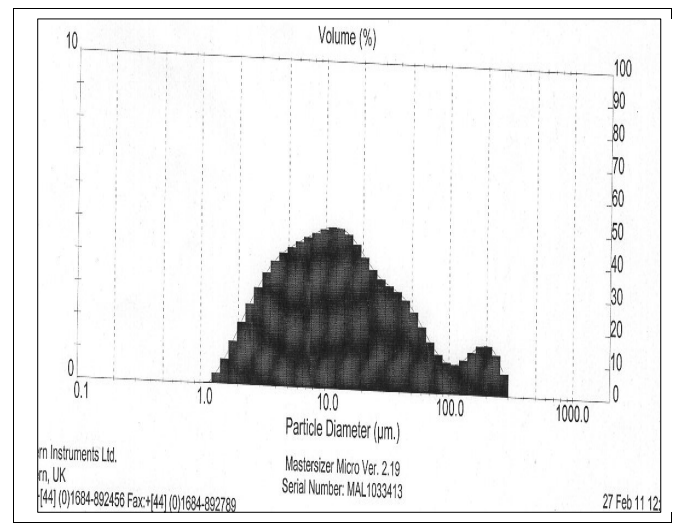

Fig. 11. Particle size distribution histogram Dy doped $\mathrm{Sr}_{2} \mathrm{CeO}_{4}$.

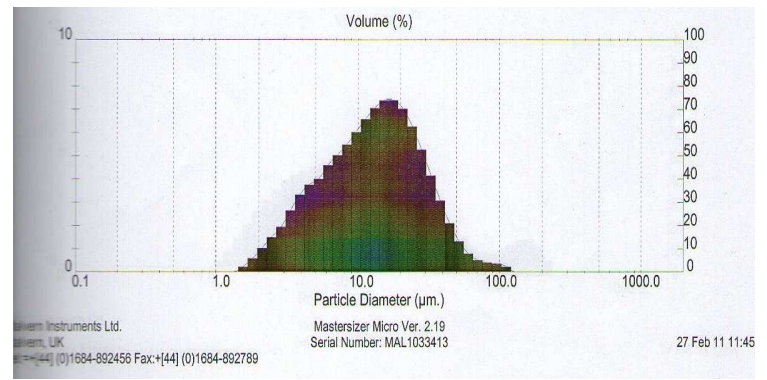

Fig. 12. Particle size distribution histogram of Eu doped $\mathrm{Sr}_{2} \mathrm{CeO}_{4}$. 


\subsection{CIE coordinates}

Based on the emission spectra, it was possible to see the color of the emission of each sample in the CIE diagrams 1931. Fig. 13 shows the CIE diagram 1931. The CIE coordinates were calculated by the spectrophotometric method using the spectral energy distribution of $\mathrm{Sr}_{2} \mathrm{CeO}_{4}$ phosphor. The CIE chromaticity index for the $\mathrm{Sr}_{2} \mathrm{CeO}_{4}$ phosphor (A) are $x=0.16$ and $y=0.18$, which is better than that reported by Danielson $(x=0.20$ and $y=0.30)$ [22] and Jiang ( $x=0.19$ and $y=0.26)$ [23], CIE chromaticity index for La $(0.5 \%)$ doped $\mathrm{Sr}_{2} \mathrm{CeO}_{4}$ phosphor (B) are $x=0.16$ and $y=0.19$, for Dy $(0.5 \%)$ doped $\mathrm{Sr}_{2} \mathrm{CeO}_{4}$ phosphor (C) are $x=0.28$ and $y=0.31$ and $\mathrm{Eu}(0.5 \%)$ doped $\mathrm{Sr}_{2} \mathrm{CeO}_{4}$ phosphor (D) are $x=0.32$ and $y=0.33$. The CIE coordinates depicted on 1931 chart reveals that the emission colour varies from blue to white with $\mathrm{Eu}(0.5 \%)$ doped $\mathrm{Sr}_{2} \mathrm{CeO}_{4}$.

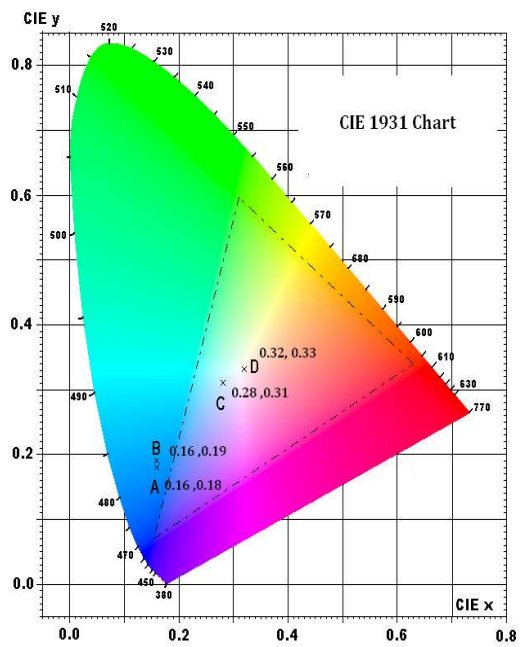

Fig.13. CIE coordinates depicted on 1931 chart where (A) $\mathrm{Sr}_{2} \mathrm{CeO}_{4}$, (B) $\mathrm{La}$ doped $\mathrm{Sr}_{2} \mathrm{CeO}_{4}$, (C) Dy doped $\mathrm{Sr}_{2} \mathrm{CeO}_{4}$, (D) Eu doped $\mathrm{Sr}_{2} \mathrm{CeO}_{4}$.

\section{Conclusions}

$\mathrm{Sr}_{2} \mathrm{CeO}_{4}$ phosphor sample is prepared by a standard solid state reaction method in air at $1200^{\circ} \mathrm{C}$. The XRD study confirms the structure of the system as orthorhombic and single phase was obtained due to the calcination temperature. The calculated average crystallite size using Scherer's formula is $\sim 10 \mathrm{~nm}$. The excitation spectrum recorded for $\mathrm{Sr}_{2} \mathrm{CeO}_{4}$ displays a broad band and peaks at $250 \mathrm{~nm}$ and $260 \mathrm{~nm}$ which is attributed to the $\mathrm{Ce}^{4+}-\mathrm{O}$ distances in the lattice The CIE coordinates depicted on 1931 chart reveals that the $\mathrm{Sr}_{2} \mathrm{CeO}_{4}$ and $\mathrm{La}$ doped phosphors exhibit blue colour, Dy doped phosphor exhibit Blue Yellow (cyan) colour and Eu doped $\mathrm{Sr}_{2} \mathrm{CeO}_{4}$ phosphor displays all colours. Therefore 
$\mathrm{Sr}_{2} \mathrm{CeO}_{4}$ doped with rare earths have good potential applications in lamps, display devices and white light LED.

\section{Acknowledgements}

This work was supported by University Grant Commission (UGC), New Delhi, India, under Faculty Development Programme (FDP).

\section{References}

1. Y. H. Wang, Z. Y. Wang, P. Y. Zhang, Z. L. Hong, and X. P. Fan, Mater. Lett. 58, 3308 (2004). http://dx.doi.org/10.1016/j.matlet.2004.06.024

2. C. Feldmann, T. Jüstel, C. R. Ronda, and P. J. Schmidt, Adv. Funct. Mater. 13, 511 (2003). http://dx.doi.org/10.1002/adfm.200301005

3. J. Yang, L. Yang, W. Liu, Y. Zhang, H. Fan, Y. Wang, H. Liu, J. Lang, and D. Wang, J. Alloys Compd. 454 (1-2), 506 (2008). http://dx.doi.org/10.1016/j.jallcom.2007.02.079

4. E. Danielson, M. Devenney, D. M. Giaquinta, J. H. Golden, R. C. Haushalter, E. W. Mcfar land, D. M. Poojary, C. M. Reaves, W. H. Weinberg, and X. D. Wu, Science 279, 837 (1998). http://dx.doi.org/10.1126/science.279.5352.837

5. C. H. Lu, C. T. Chen, J. Sol-Gel Sci. Technol. 43,179 (2007). http://dx.doi.org/10.1007/s10971-007-1565-3

6. S. L. Fu, J. Dai, and Q. K. Ding, J. Inorg. Mater. 2, 357 (2006).

7. Z. Yongqing, Z. Xueling, Y. Guozhong, M. Yuan, Y. Sumei, and G. Zaihong, J. Rare Earths 24, $281(2006)$.

8. L. Li, S. Zhou, and S. Zhang, Chem. Phys. Lett. 453, 283 (2008). http://dx.doi.org/10.1016/j.cplett.2008.01.033

9. P. N. Yocom, Electrochem. Soc. Interface 3, 26, (1994).

10. X. Yu, X. H. He, S. P.Yang, X.Yang, and X. Xu, Mater Lett. 58, 48 (2003). http://dx.doi.org/10.1016/S0167-577X(03)00412-9

11. R. Sankar and G. V. Subba Rao, J. Electrochem. Soc. 147, 2773 (2000). http://dx.doi.org/10.1149/1.1393605

12. Y. D. Jiang, F. Zhang, and C. J. Summers., Appl. Phys. Lett. 74, 1677 (1999). http://dx.doi.org/10.1063/1.123652

13. X. Liu, Y. Luo, J. Lin, J. Cryst. Growth 290, 266 (2006). http://dx.doi.org/10.1016/j.jcrysgro.2005.12.091

14. K. Suresh, K. V. R.Murthy, Ch. Atchyutha Rao, and N. V. Poornachandra Rao, ISRN Cond. Matter Phys. ID 392917,1- 3, (2011). http://dx.doi.org/10.5402/2011/392917

15. W. M. Yen and M. J. Weber, Inorganic Phosphors: Composition, Preparation and Optical Properties (CRC Press. Boca Raton, FL, USA, 2004). http://dx.doi.org/10.1201/9780203506325

16. H. Bechtel, T. Justel, H. Glaser, and D. U. Wiechert, J. SID, 10, 63 (2002).

17. CDD Powder Diffraction, Card No.89-5546.

18. K. Suresh, K. V. R. Murthy, Ch. Atchyutha Rao, N. V. Poornachandra Rao, and B. Subba Rao, J. Lumines. 133, 96 ( 2013).

19. C. X. Zhang, W. J. Jiang, X. J. Yang, Q. F. Han, and Q. L. Hao, J. Alloys Compd. 474, 287, (2009). http://dx.doi.org/10.1016/j.jallcom.2008.06.061

20. Y. X. Tang, H. P. Guo, and Q. Z. Qin, Solid state Commun. 121, 352 (2002). http://dx.doi.org/10.1016/S0038-1098(02)00016-9

21. Ch. Atchyutha Rao, K. V. R. Murthy, and N. V. Poornachandra Rao, Adv. Mater. Appl. Macmillan Advanced Series Publisher, ISBN CORP-OOO187, 1147 (2011). 
22. E. Danielson, M. Devenney, D. M. Giaquinta, J. H. Golden, R. G. Haushalter, E. W. McFarland, D. M. Poojary, C. M. Reaves, W. H. Weinberg, and X. Di Wu, J. Mol. Struct. 470, 229 (1998). http://dx.doi.org/10.1016/S0022-2860(98)00485-2

23. Y. D. Jiang, F. Zhang, C. J. Summers, and Z. L. Wang, Appl. Phys. Lett. 74 (12), 1677 (1999). http://dx.doi.org/10.1063/1.123652 